\title{
SIMULATION ANALYSIS OF PREHEATER CHARGE TO THE ROTARY FURNACE
}

\author{
Jan Mikula*, Pavol Palicka, Jan KerekaniC
}

Development and realization workplace of raw materials extracting and treatment, Faculty of mining, ecology, process control and geotechnology, Technical University of Kosice, Nemcovej 32, 040 02 Kosice, Slovak Republic

* corresponding author: jan.mikula@tuke.sk

Abstract. Mathematical modeling of heat aggregates is one of the fundamental methods of the mathematical modelling research. A mathematical model based on the method of elementary balances was created for the thermal treatment of granular and lumpy materials. The adaptation of the selected aggregate model is based on prior knowledge and experiments. The paper presents an adaptation of the mathematical model for the magnesite processing rotary furnace using the mode of caustic and clinker production. A simulation of the charge preheater impact based on the thin layer principle is implemented into the model. The main advantages of using this type of preheater of rotary furnace are smaller dimensions for a large exchange surface and low pressure losses.

KEYWORDS: rotary furnace, mathematical model, preheater, magnesite.

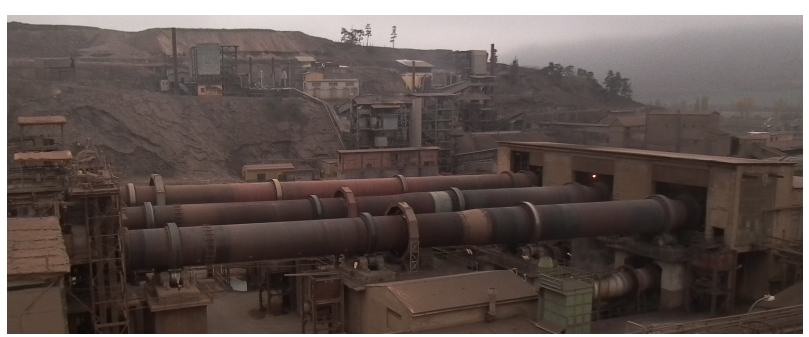

FiguRE 1. Rotary furnaces for magnesia sintering.

\section{INTRODUCTION}

Magnesite raw material processed by the SMZ Jelsava a.s. company is an isomorphic mixture of magnesite with siderite - breuneritic magnesite type. A dolomit is the main accompanying mineral. The magnesite concentrates, whose standard of quality in terms of chemical composition is shown in Table 1 The rotary furnaces for magnesite firing (Fig. 1) 1, 2,

The rotary furnaces of the SMZ, a.s Jelsava company use their current technological possibilities. However, their work is far from the technological optimum. The energy costs for sintered magnesia firing present a crucial expense. To improve the current situation, an optimization program for rotary furnace operation has been developed. The installation of a charge pre-

\begin{tabular}{lcccc}
\hline Concentrates & $\begin{array}{c}\mathrm{MgO} \\
(\min )\end{array}$ & $\begin{array}{c}\mathrm{CaO} \\
(\max )\end{array}$ & $\begin{array}{c}\mathrm{Fe}_{2} \mathrm{O}_{3} \\
(\max )\end{array}$ & $\begin{array}{c}\mathrm{SiO}_{2} \\
(\max )\end{array}$ \\
\hline $\mathrm{K} 11_{1-10}$ & 43.0 & 2.7 & 3.8 & 0.5 \\
\hline $\mathrm{K} 11_{10}-40$ & 43.5 & 2.2 & 3.8 & 0.4 \\
\hline $\mathrm{K} 210-40$ & 41.3 & 3.0 & 3.9 & 0.6 \\
\hline
\end{tabular}

TABLE 1. Quality regulation for rotary kiln batch (values in \%).

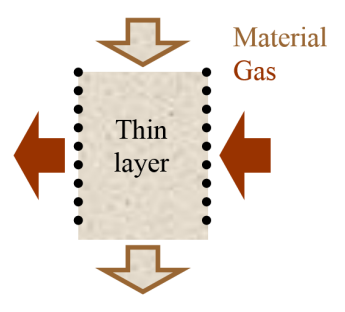

Figure 2. The principle of medium flow in a thin layer.

heater for the rotary furnace working on the principle of a thin layer is one of the measures included in an optimization program (Fig. 2] [3, 4].

The layer thickness of the material depends on the maximum grain size and on the rheological properties of the material. The minimum thickness of the material layer should be no less than three times the maximum grain size. The principle of a thin layer ensures better material or energy efficiency, and a large exchange surface due to direct contact of individual grains with the gaseous medium (better transmission parameters). The effect of charge preheating on the technological processes can be assessed using mathematical modeling and simulation. The parametric model adequacy is associated with sufficient available information from the production that takes into account the specific characteristics of the modeled object and is useful in the extrapolation region.

\section{Mathematical model of The GRANULAR MATERIALS THERMAL TREATMENT}

The mathematical model consists of partial models of the equipment which can be combined using the proposed technology (Fig. 3). Partial models were already applied during the model generation, which 


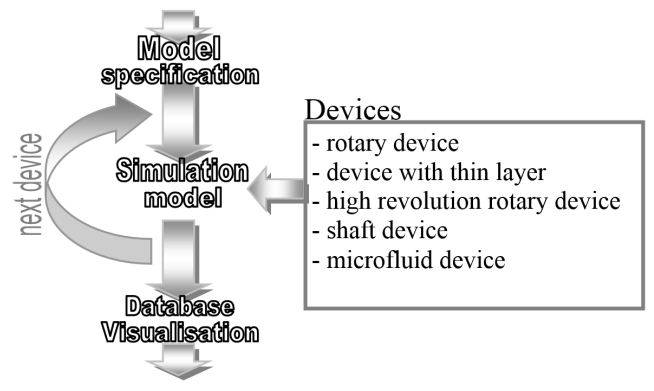

FIGURE 3. Simulation model generation.

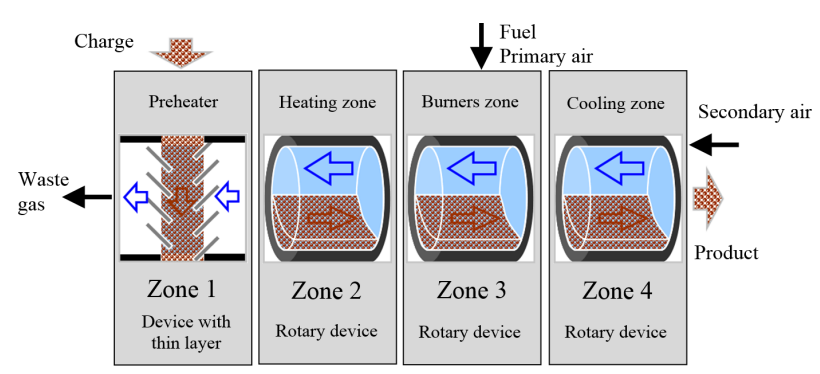

Figure 4. Example of the model arrangement of a rotary furnace with preheater and cooler.

had an influence on the method selection [5]. The elementary balances method for sequential model had been chosen. The model used the replacement partial models, where resolving power is given by size of elementary particles and by the option of partial processes models. For this reason the thermal apparatus is decomposed into zones and elements [6, 17].

A high quantity of simulation alternatives can be created by arranging the zones and the parameters, or the media flow directions. The mathematical model contains the components for the rotary furnace simulation with the preheater and cooler (Fig. 44 [8, 9].

We took into consideration the technological process at which treated material is passing through the apparatus and the processes are realized by their mutual interaction [10]. Thermal processes carried out in the thermal aggregates are modelled using the elementary balances method. For the magnesia thermal treatment rotary furnace of SMZ Jelsava, a gas flowing is countercurrent. The heating process model includes a heat transfer between the gas and the material and heat conduction in the material 11 .

The following relations were used:

- Convective heat transfer [12]:

$$
Q=F \alpha \Delta t ; \quad \alpha=f\left(\Re, \operatorname{Pr}, \lambda, d_{h}\right)
$$

where $F$ - heat exchange area, $\alpha-$ convective heat transfer coefficient $\left[\mathrm{W} \mathrm{m}^{-2} \mathrm{~K}^{-1}\right], \Delta t-$ temperature gradient between heat exchange areas, $\Re$ Reynolds number, $\operatorname{Pr}$ - Prandtl criteria, $\lambda$ - heat conductivity $\left[\mathrm{W} \mathrm{m}^{-1} \mathrm{~K}^{-1}\right], d_{h}$ - average material diameter.

- Conductive heat transfer [13, 14]:

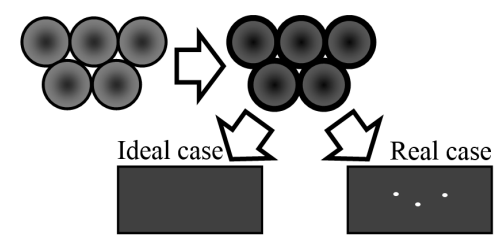

Figure 5. The sintering process a) real case (creating closed pores); b) ideal state (without pores).
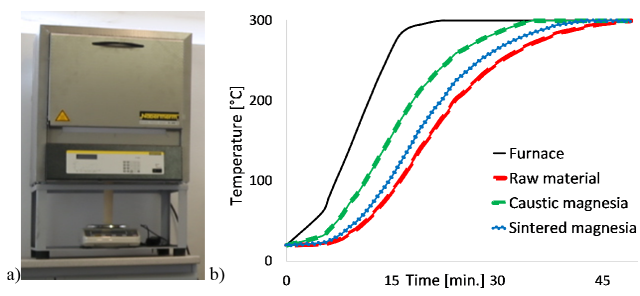

Figure 6. Laboratory determination of the spread of heat transfer, a) equipment; b) course of curves.

$$
Q=F \lambda \frac{d t}{d x} \tau
$$

where $d t$ - layer temperature, $\tau$ - timestep.

- Decarbonization of magnesite [15, 16]:

$\triangleright$ siderite is decomposed at $350^{\circ} \mathrm{C}: \mathrm{FeCO}_{3}=\mathrm{FeO}+$ $\mathrm{CO}_{2}$, reaction heat $714 \mathrm{~kJ} \mathrm{~kg}^{-1}$;

$\triangleright$ magnesite decomposition starts at $399{ }^{\circ} \mathrm{C}$ when the equilibrium partial pressure $\mathrm{CO}_{2}$ is achieved over $\mathrm{MgCO}_{3}$. Because of the presence of $\mathrm{CO}_{2}$ in the atmosphere, magnesite is unstable even at $250^{\circ} \mathrm{C}$. Decomposition takes place at the temperature maximum $650-700^{\circ} \mathrm{C}: \mathrm{MgCO}_{3}=\mathrm{MgO}+$ $\mathrm{CO}_{2}$, reaction heat $1381 \mathrm{~kJ} \mathrm{~kg}^{-1}$;

$\triangleright$ decomposition of $\mathrm{CaCO}_{3}$ included in dolomite begins at about $883^{\circ} \mathrm{C}: \mathrm{CaCO}_{3} \cdot \mathrm{MgCO}_{3}=\mathrm{CaO}+$ $\mathrm{MgO}+2 \mathrm{CO}_{2}$, reaction heat $1767 \mathrm{~kJ} \mathrm{~kg}^{-1}$.

- The sintering of magnesite charge [17]: At the beginning of the sintering temperature $\left(1300^{\circ} \mathrm{C}\right)$, the recrystallization of amorphous $\mathrm{MgO}$ to periclase occurs (see Fig. 5). The degree of magnesite sintering is presented by bulk density, which reaches a maximum value of $3.58 \mathrm{~g} \mathrm{~cm}^{-3}$. In real cases, the value of $3.40 \mathrm{~g} \mathrm{~cm}^{-3}$ is reached.

\subsection{IDENTIFICATION OF MODEL PARAMETERS}

The parameters for the mathematical model can be obtained by laboratory experiments, operating values analysis from the information system or measurement on the device.

Determination of heat transfer coefficient for the mathematical model. Magnesite samples were heated in the furnace space by gradual increase of the temperature to the temperature of $300{ }^{\circ} \mathrm{C}$ (see Fig. 6). The aim was to investigate the changes in temperature in the middle of individual magnesite 
a)
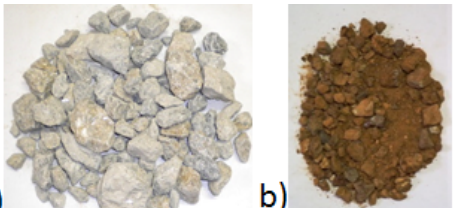

b)

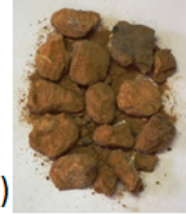

Figure 7. Grain size analysis K2 10-40 mm: a) starting raw magnesite material; b) after annealing the granularity samples $31,5 \mathrm{~mm}$ maximum; c) after annealing the granularity samples $31,5 \mathrm{~mm}$ minimum.

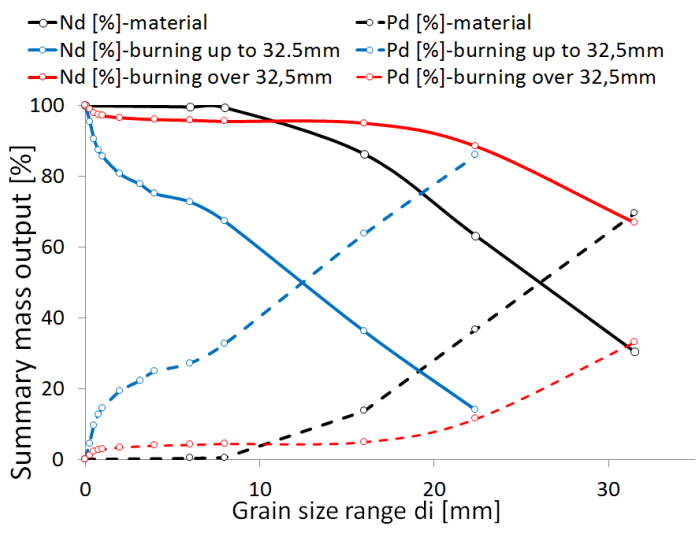

FiguRE 8. Distribution curve of the dependence of summary weight yield from granulometric range oversize $(\mathrm{Nd})$ a undersize fraction $(\mathrm{Pd})$.

samples by temperature transfer from the surface to the center of the sample (thermal conductivity). During the experiment as the heat source was used the laboratory annealing furnace Nabertherm P300 was used as the heat source. With the temperature of $\sim 20^{\circ} \mathrm{C}$, the samples were gradually heated (raw magnesite material, caustic, clinker). The grain class of individual samples was $<0.5 \mathrm{~mm}$ with a volume of about $30 \mathrm{~cm}^{3}$.

The thermal conductivity coefficient for the individual samples was determined based on the experiment results:

- Raw material: $3.5 \mathrm{~W} \mathrm{~m}^{-1} \mathrm{~K}^{-1}$,

- Caustic: $6 \mathrm{~W} \mathrm{~m}^{-1} \mathrm{~K}^{-1}$,

- Clinker: $4.5 \mathrm{~W} \mathrm{~m}^{-1} \mathrm{~K}^{-1}$.

Grain size analysis of raw materials. The grain size analysis of raw material K2 10-40 (Table1, Fig. 7) was carried out in the laboratories of Development and Realization of RMET at firing temperature of $900^{\circ} \mathrm{C}$ and for a time of 2.5 hours. The sample was divided according to thickness of fraction of below and above $31.5 \mathrm{~mm}$.

In the mathematical model, it is possible to take into account the change in the exchange area, which varies during the magnesite firing based on the distribution curve (Fig. 8) related to the dependence of the summary weight yield on the from granulometric range - oversize $(\mathrm{Nd})$ a undersize fraction $(\mathrm{Pd})$.

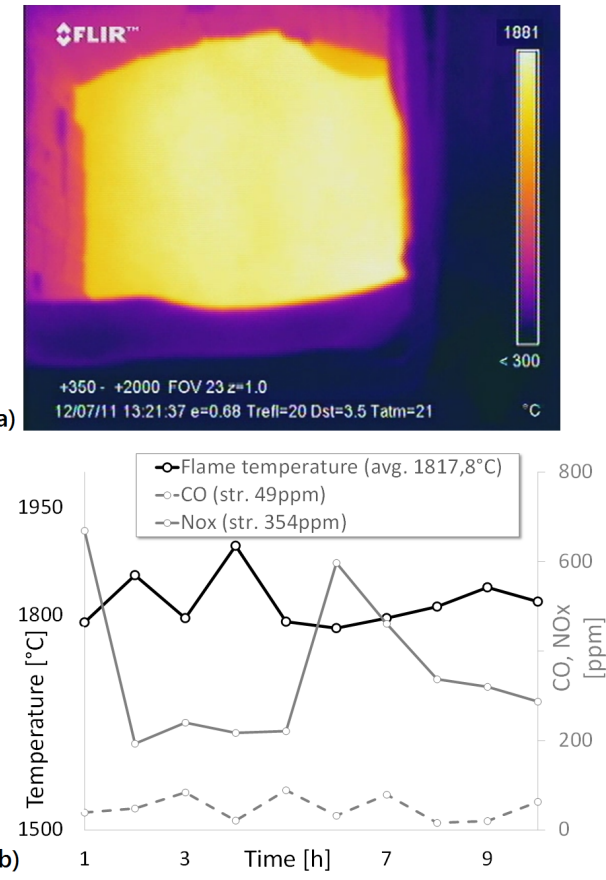

Figure 9. Measurement at the sintering regime a) thermal camera - warm head; b) course of temperatures and change of the flue gas composition.

Operating data. Apart from laboratory measurements, data acquired from the monitoring system and by measurements in operation (Tab. 2 has been obtained for the mathematical model calibration. For the monitoring and control of rotary furnaces, the SMZ Jelsava, a.s. enterprise uses the SattControl system of the company $\mathrm{ABB}$, which was introduced in 2001 and is used for rotary furnaces No. 1, 2 and 3.

Methods for the obtainment of operating parameters:

- operating continuous measurement (PM),

- single measurement (JM),

- laboratory measurement (LM).

A sample measurement of the maximum flue gas temperature through the warm head of rotary furnace No. 2 of the SMZ Jelsava, a.s. company is shown in Fig. 9 [18.

\section{Results And Discussion}

The mathematical model of the rotary furnace No.2 for the magnesite processing of K2 concentrate from 10 to $40 \mathrm{~mm}$, for the furnace regime of clinker and caustics production, has been calibrated based on the acquired knowledge. A comparison of the mathematical model and of the measurements in terms of material and flue gas temperature is shown in Fig. 10.

While maintaining the calibration parameters for the reference process, a state with an installed preheater was simulated. A preheater developed for the Developmental and Realisation Workplace of RMET of the faculty of MEPCG, Technical University of 


\begin{tabular}{|c|c|c|c|}
\hline Parameter & Method & Type & Unit \\
\hline Charge analysis & LM & input & $\%$ \\
\hline Granularity & LM & input & $\mathrm{mm}$ \\
\hline Charge number & $\mathrm{PM}$ & input & $\mathrm{t} / \mathrm{h}$ \\
\hline Input of natural gas & PM & input & $\overline{\mathrm{Nm}^{3} / \mathrm{h}}$ \\
\hline Primary air & $\mathrm{JM}$ & input & $\overline{\mathrm{Nm}^{3} / \mathrm{h}}$ \\
\hline Burner-entry oxygen & $\mathrm{PM}$ & input & $\mathrm{Nm}^{3} / \mathrm{h}$ \\
\hline Amount of secondary air & $\mathrm{JM}$ & input & $\mathrm{Nm}^{3} / \mathrm{h}$ \\
\hline Temperature of secondary air & $\mathrm{JM}$ & input & ${ }^{\circ} \mathrm{C}$ \\
\hline Intake of air on the warm head & - & input (desired) & $\overline{\mathrm{Nm}^{3} / \mathrm{h}}$ \\
\hline $\begin{array}{l}\text { Amount of output flue gas } \\
\text { (without latch on the cold head) }\end{array}$ & - & input (desired) & $\overline{\mathrm{Nm}^{3} / \mathrm{h}}$ \\
\hline $\begin{array}{l}\text { Amount of output flue gas } \\
\text { (without latch on the cold head) }\end{array}$ & - & output (desired) & ${ }^{\circ} \mathrm{C}$ \\
\hline Intake of air on the cold head & - & input (desired) & $\mathrm{Nm}^{3} / \mathrm{h}$ \\
\hline Sucked flue gas volume & $\mathrm{PM}$ & output & $\overline{\mathrm{Nm}^{3} / \mathrm{h}}$ \\
\hline Amount of $\mathrm{O} 2$ in flue gas & $\mathrm{JM}$ & output & $\%$ \\
\hline Temerature of output flue gas & $\mathrm{PM}$ & output & ${ }^{\circ} \mathrm{C}$ \\
\hline Amount of flue dust & $\mathrm{JM}$ & output & $\mathrm{kg} / \mathrm{h}$ \\
\hline Temperature of output material & PM & output & ${ }^{\circ} \mathrm{C}$ \\
\hline Temperature of flame & $\mathrm{JM}$ & output & ${ }^{\circ} \mathrm{C}$ \\
\hline Maximum temperature of material & $\mathrm{JM}$ & output & ${ }^{\circ} \mathrm{C}$ \\
\hline Amount of product & $\mathrm{PM}$ & output & $\mathrm{t} / \mathrm{h}$ \\
\hline
\end{tabular}

TABLE 2. Basic rotary furnace parameters, and methods to obtain them for the mathematical model calibration.

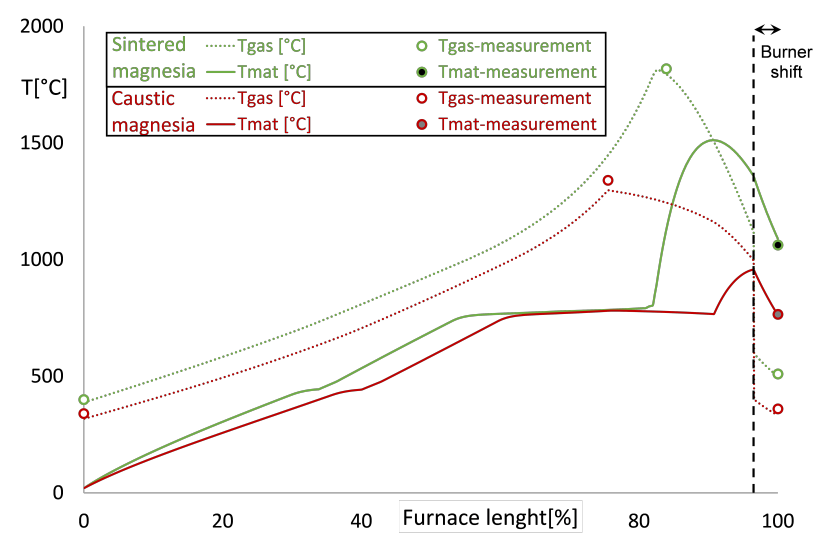

Figure 10. Course of material and flue gas temperaturesat the calibrated model.

Kosice (see Fig. 13), working on the principle of a thin layer, was considered. The advantages of the preheater are low pressure losses with a high exchange surface and a small built-up area. In comparison with the competitive solutions, the layer is oriented vertically. The designed preheater has a working layer volume of $4.5 \mathrm{~m}^{3}$. The course of temperatures is shown in

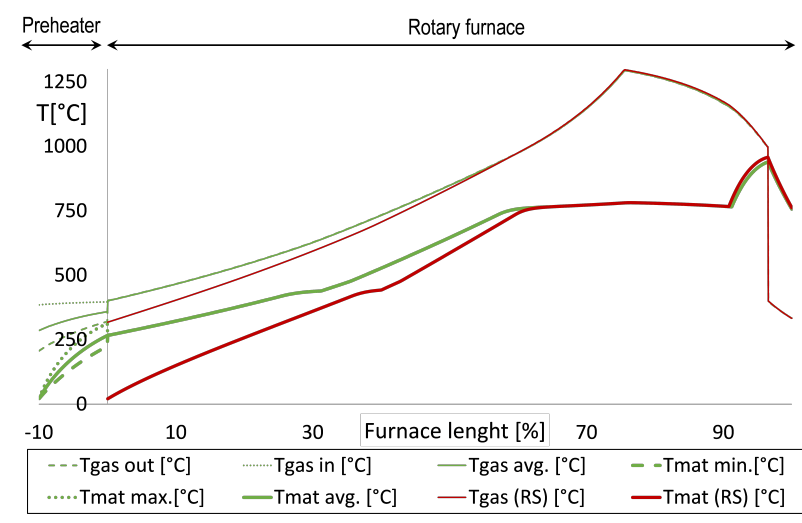

Figure 11. Caustic production - comparison of the course of temperatures of a standard operation (reference state) and while using a preheater.

Fig. 11 for the regime of caustic production and in Fig. 12 for clinker production.

Based on the simulations, we expect a contribution related to the installed preheater. In relation to the input, we expect an increase in the performance of the rotary furnace for the production of caustic magnesia 


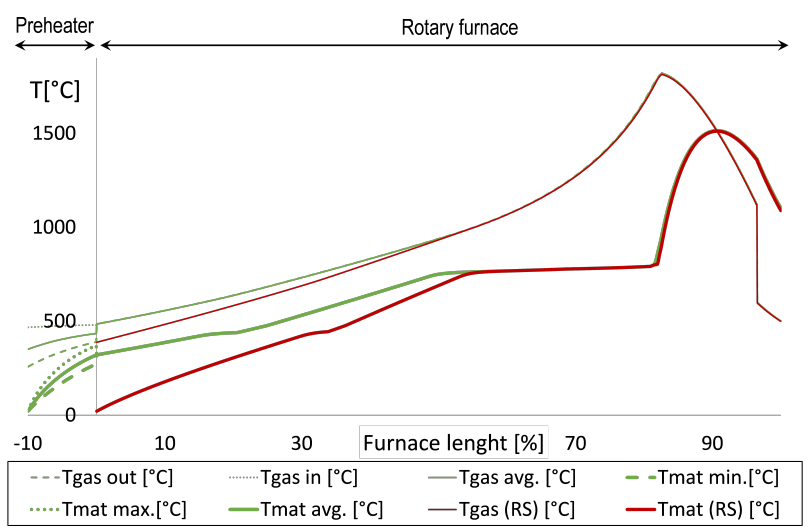

FigURE 12. Clinker production - comparison of the course of temperatures of a standard operation (reference state) andwhile using a preheater.

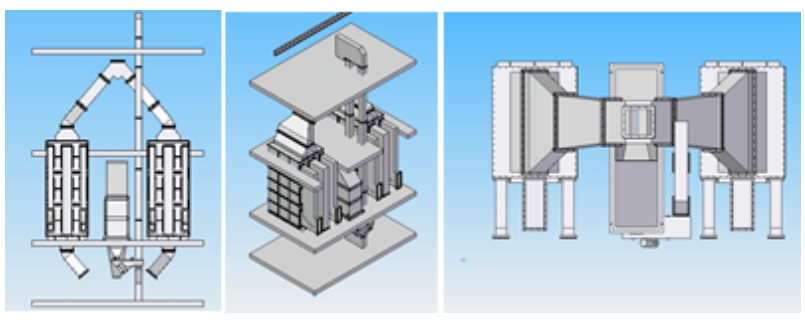

FiguRE 13. Visualisation of preheater based on the principle of thin layer for the rotary furnace No. 2 .

of $4.2 \%$. Due to the high temperature of the material going into the rotary furnace, losses through the walls are increased on average by $2.6 \%$, while the expected increase in flue dust is $4.2 \%$. For the production of sintered magnesia, the expected increase in output is $3.9 \%$, with an increase in flue dust of $3.9 \%$ and an increase in losses through the wall of $2.7 \%$.

\section{Conclusions}

In this paper, the problems of the production of caustic and sintered magnesia in rotary furnaces increase their thermal efficiency. The furnaces of the SMZ Jelsava, a.s. company have been considered as reference aggregates. The outgoing flue gas temperature is in the range of $450-550^{\circ} \mathrm{C}$. The designed preheater will increase the efficiency of the furnace by $3.9 \%$ relative to the production of sintered magnesia. The increase in efficiency in the production of caustic magnesia is $4.2 \%$. The preheater concept based on the principle of compact thin layer satisfies rheological, hydromechanical and thermodynamic requirements. The operating preheater has been designed based on the realised simulations.

\section{ACKNowledgements}

This contribution is the result of the implementation of the Research Excellence Centre on Earth Sources, Extraction and Treatment project supported by the Research \& Development Operational Programme funded by the ERDF (ITMS: 26220120017).

\section{REFERENCES}

[1] I. Kostial, J. Spisak, J. Mikula, et al. Advanced process manipulation of magnesia sintering. Proceedings of the 17th World Congress, The International Federation of Automatic Control, Seoul, Korea p. 5, 2008.

[2] A. Babjakova, R. Repisky, D. Dorcak. Balance sheet optimizing model of the magnesite process modification in smz, a.s. jelsava. 14th Conference on Environment and Mineral Processing, Part 2, VSB-TU, Ostrava, Czech Republic, ISBN 978-80-248-2209-9 p. 6, 2010.

[3] M. Zelko, D. Dorcak, M. Husarova, A. Olijar. The proposal of new technology within the concept of "invisible mine". 14th Conference on Environment and Mineral Processing: VSB-TU, Ostrava, Czech Republic p. 6, 2010.

[4] P. Kosinar, et. al. Praxes needs in the area of research and development in smz, a.s. jelsava. Advance technologies of raw material mining and threatment, 1 st scientific symposium: Proceedings of the lectures, Hradok at Jelsava, TU, Kosice, ISBN 978-80-553-0635-3 p. 4, 2011.

[5] I. Kostial, J. Terpak, J. Spisak, et al. Advanced process manipulation. 8th International Carpatian Control Conference, Strbske Pleso-Slovak republic p. 12, 2007.

[6] J. Mikula, et. al. Mathematical modelling of lumpy and granular material thermal treatment. Acta Metallurgica Slovaca, vol 15, no 1, ISSN 1335-1532 p. 7, 2009.

[7] D. Nascak, J. Mikula, I. Kostial, et al. Acceleration of simulation models for raw materials thermal treatment. 12th International Carpathian Control Conference p. 5, 2011.

[8] J. Mikula, et. al. Generation of mathematical hierarchical models for virtual reality environment. ICCC'2009, AGH - University of science and Technology Zakopane,Krakow, Poland, ISBN 8389772-51-5 p. 3, 2009.

[9] I. Kostial, J. Terpak, J. Mikula. Surrogate modelling of processes for granular material thermal treatment. IFAC WORKSHOP MMM'2006, Cracow, Poland p. 5, 2006.

[10] G. K. Mishkoy. Modeling and analysis of losses within the switching process in real-time systems. Proceedings of the IEEE International Symposium on Industrial Electronics p. 2, 1992.

[11] I. Kostial, L. Dorcak, J. Terpak. Optimal control of the sintering process. Preprints of the 16th IFAC World Congress, Prague, Czech Republic p. 6, 2005.

[12] J. Staron, F. Tomsu. Refractory materials-productions, properties and usage. Second printing. Radovan Mlynarik-MEDIA, Banska Bystrica, Slovakia, 2000.

[13] M. Michejev. Fundamentals of Heat sharing. Second printing. Industrial publishing, Praha, CzechoSlovakia, 1953.

[14] Z. Vaszi, A. Varga. Mathematical model for determining the characteristics of compressors. Acta Metallurgica Slovaca, vol15, no1, ISSN 1335-1532 p. 6, 2009.

[15] I. Kostial, J. Terpak, J. Mikula. Behavioural modelling of complex thermal systems. 6th International Carpathian Control Conference, Miskolc-Lillafured, University of Miskolc, Hungary p. 5, 2005. 
[16] I. Barin. Thermochemical Data of Pure Substances. First printing. VCH, New York, ISBN 3-527-28531., 1993.

[17] A. Olijar, J. Spisak, M. Behun. Thermal sintering regimes and treatment regimes in the dependence of threaded material and requirements on the products. Advance technologies of raw material mining and treatment, 1st scientific symposium: Proceedings of the lectures, Hradok at Jelsava, Slovakia, ISBN

978-80-553-0635-3 p. 5, 2011.
[18] V. Maduda, et. al. Increasing of thermal efficiency of the thermal apparatus. in: Advance technologies of raw material mining and treatment. 1st scientific symposium, Proceedings of the lectures, Hradok pri Jelsave, Kosice, TU, ISBN 978-80-553-0635-3 p. 3, 2011. 